\title{
Effect of gamma irradiation on the morphological and physiological variation from In vitro individual shoot of banana cv. Tanduk (Musa spp.)
}

\author{
Ferid Abdulhafiz $\cdot$ Fatimah Kayat $\cdot$ Suhana Zakaria
}

Received: 16 October 2017 / Revised: 12 March 2018 / Accepted: 9 April 2018

(c) Korean Society for Plant Biotechnology

\begin{abstract}
Inducing genetic and morphological variation through conventional method is very difficult. Therefore, mutation induction through in vitro technology brings numerous advantages over the conventional breeding. Thus, the individual shoots $(1 \sim 2 \mathrm{~cm})$ were irradiated with gamma rays $(10 \sim 70$ Gy). The result revealed that the explants treated with higher doses (40, 50, 60, and $70 \mathrm{~Gy})$ showed deleterious effects of ionizing radiation. The highest survival rate among $\gamma$ treated explants recorded was $71 \%$ in 10 Gy treatments while the lowest survivality was $15 \%$ in $70 \mathrm{~Gy}$. Lethal dose $50 \%\left(\mathrm{LD}_{50}\right)$ dose was found to be $33 \mathrm{~Gy}$. In the in vitro condition, rooting reponse showed that increase in gamma irradiation dose resulted in the inhibition of root growth. Meanwhile, non-treated explants had the best rooting ability with the maximum number of root per explant (20) within a short period of time (6 days), with the highest root length of $(15.1 \mathrm{~cm})$. The longer period in rooting (12 days) and lowest number of root per explant (8) with shortest root length (10.1 $\mathrm{cm})$ were recorded at $30 \mathrm{~Gy}$ treatment. The highest shoot length $(13.6 \mathrm{~cm})$ was observed at control treatment and the shortest shoot length $(10.4 \mathrm{~cm})$ was observed at $30 \mathrm{~Gy}$. In the nursery, lowest leaf number (5) was observed at $30 \mathrm{~Gy}$ compared with other treatments. The highest chlorophyll content (49.8) was recorded at 10 Gy treated seedling. Irradiated explants with $10 \mathrm{~Gy}$ found to be superior over the control treatment and had positive effects in main growth parameters such as chlorophyll content.
\end{abstract}

Keywords Tanduk, $\mathrm{LD}_{50}$, mutation breeding, In vitro

F.Abdulhafiz $(\bowtie) \cdot$ F.kayat $\cdot$ S. Zakaria

Faculty of Agro Based Industry, University Malaysia Kelantan,

17600, Jeli, Kelantan, Malaysia

e-mail: feridabdul24@gmail.com

\section{Introduction}

Banana and plantains (Musa spp.) are important staple food crops for many people throughout the developing world and major source of nutrition for many people. Cultivar Tanduk is one of the popular banana varieties in Malaysia and widely cultivated by smallholders for production of banana used for the purpose of industrial processing. In banana production industry, the necessity to develop new commercially acceptable banana is still in a concern. Most of existing banana cultivars needs to be improved for some agronomical characteristics such as high yield, early flowering, better physical attributes and quality of fruit. However, it is not easy to fulfill the demands of both domestic and international markets without employing new approach. The conventional breeding of most commercially demanded banana is handicapped due to a complex genetic background, lack of seed formation, parthenocarpic nature and triploidy factors that hamper the improvement of this crop with the desired quality (Kumar, 2006). However, the development of plant cell, tissue culture and mutation breeding using in vitro mutagenesis technique over the last 20 years has made it possible to transfer part of the conventional breeding work from field to laboratory conditions. In vitro mutation breeding can support in overwhelming hurdles in the progress of new and superior banana cultivars for sustainable and continuous fruit production without disease spread (Javed et al. 2004). Through this technology a large number of improved mutant varieties have been released for commercial cultivation in many crops demonstrating the economic value of the mutation breeding technology (Kharkwal and Shu 2009; Jain and Suprasanna 2011).

Gamma rays are the most commonly used mutagenic agent in an in vitro mutagenesis experiment (Roux et al. 2004) since it has higher degree of accuracy, sufficient reproducibility and deep penetrating power into a biological matter that can cause a greater number of variation in physio- 
chemical composition (Yamaguchi, 2003). Biological effect of gamma radiation depends on atoms or molecules interaction inside the cell, especially water, to produce free radicals (Kovacs and Keresztes 2002). These radicals could harm or adjust main components of plant cells and disturb the physiochemical and biochemical process of plants depending on the radiation level (Ashraf et al., 2004). Gamma rays could restructure plant cell and metabolism include thylakoid membranes dilation, modification in photosynthesis, adjustment of the anti-oxidative structure, and accumulation of secondary metabolite (Ashraf et al. 2004; Kovacs and Keresztes 2002; Mbaye, 2017).

In vitro mutagenesis refers to mutations induced by treating explants or in vitro cultures with a mutagen, followed by mutant screening and characterization. This process involves a sequence of essential steps: choice of proper target plant material (explants or cultures); choice of a mutagen and determination of a suitable dose, post-treatment management and a series of subculture, and regeneration of plants for mutant selection. Mutagenic treatments can be applied to explants or in vitro cultures such as multiple shoot cultures, callus, cell suspensions, protoplasts and microspores and a variety of explants can be also used such as apical meristems, axillary buds, roots and tubers. In a principle, all kind of plant material used for mutagenic treatment, whether from explants or in vitro cultures are needed to undergo a series of subcultures after being mutagenized to separate chimeras and produce plants for selection of desired mutants since mutation remains undetectable by chimeras in the first generation (Banerjee et al. 2015).

However, in the recent studies by Karmarkar et al. (2001), who had made an attempt to induce mutation using in vitro individual shoot, the researcher had exposed in vitro individual shoot to gamma radiation followed by sub culturing on rooting medium without undertaking sub-culture processes to examine the post-irradiation rooting response in the laboratory condition. However, he could not go further and observe the explants response to gamma irradiation in the nursery stage. The present study was conducted to fill this gap. Thus, the individual shoot was singled out from multiple shoot culture and mutagenized with gamma radiation and then immediately transferred to rooting medium without undertaking sub-culture. The post-radiation rooting response and growth performance were studied in the laboratory condition and nursery stage. Hence, the present study was conducted to study the effect of different dose of gamma rays on the in vitro individual shoot growth performance under in vitro and nursery condition.

\section{Material and Methods}

Gamma exposure, culture condition and acclimatization of mutated plantlets

The sword sucker of banana cultivar Tanduk $(25 \sim 35 \mathrm{~cm})$ in height approximately $3 \sim 4$ months old were used. Shoot tip culture were established and maintained until fourth $\left(\mathrm{M}_{1} \mathrm{~V}_{4}\right)$ sub-culture cycle using MS medium supplemented with $5 \mathrm{mg} / \mathrm{l} \mathrm{BAP}$. Individual shoot $(1 \sim 2 \mathrm{~cm}$ in length) were isolated and used as explant (Fig. 1). The roots, necrotic tissue and traces of solidifying agent were removed from the explant and then placed in the sterile Petri dish wetted with distilled water. The individual shoot in the Petri dishes were irradiated with different doses of gamma $(\gamma)$ rays (10, 20, 30, 40, 50, 60 and 70 Gy) using Cesium-137 source at a dose rate of $5.5 \mathrm{Grey} /$ minute to study the radiosensitivity. The total samples of (140) individual shoot were irradiated and the final treatment were selected after this test. The treated explants were then washed thoroughly with sterilized distilled water prior to culture and then cultured aseptically on MS medium fortified with $2 \mathrm{mg} / 1$ activated charcoal to regenerate into complete plantlets. The basal medium contained inorganic salts of MS (Murashige and Skoog, 1962) plus Myo-inositol $100 \mathrm{mg} / \mathrm{L}$, Nicotinic Acid $0.5 \mathrm{mg} / \mathrm{L}$, Pyridoxine HCL $0.5 \mathrm{mg} / \mathrm{L}$, Thiamine $\mathrm{HCl}$ $0.5 \mathrm{mg} / \mathrm{L}$, Glycine $2.00 \mathrm{mg} / \mathrm{L}$ and sucrose $30 \mathrm{~g} / \mathrm{L}$. The $\mathrm{pH}$ was adjusted to 5.7 prior to adding Agar $(7 \mathrm{~g} / \mathrm{L})$. All cultures were incubated in the culture room at $25 \pm 2^{\circ} \mathrm{C}$ and $55 \sim 65 \%$ relative humidity with photoperiod of 16 hours light under fluorescent light (1000 lux) and 8 hours dark.

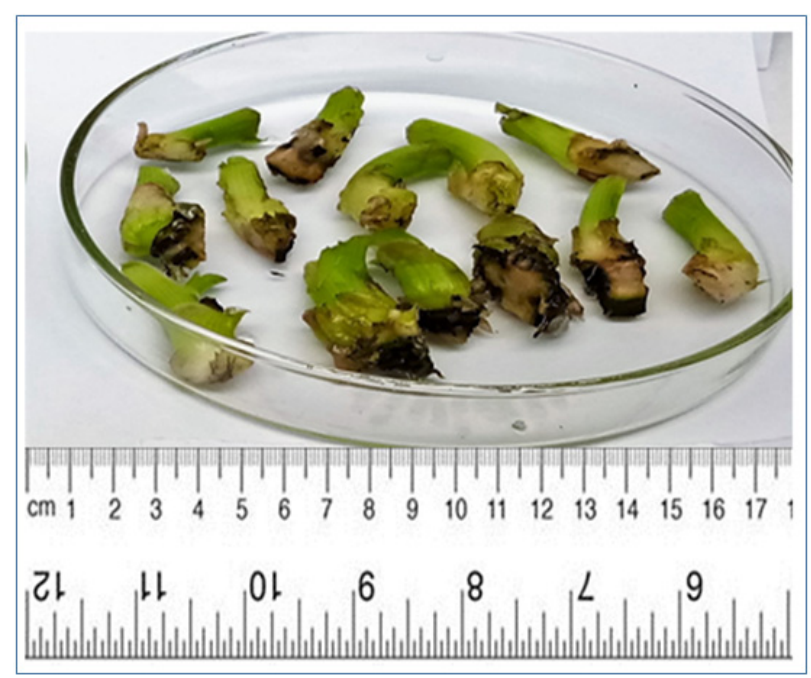

Fig. 1 Individual shoot explant. 
After 4 weeks, well grown rooted plantlets $(7 \sim 9 \mathrm{~cm}$ in length) were carefully removed from the culture vessel and then the roots were washed thoroughly in tap water to remove the traces of nutrients and were transplanted in the greenhouse in polybags containing a ratio 2:1 mixture of peat moss and coco peat.

Experimental observation and statistical analysis

The $\mathrm{LD}_{50}$ values were determined based on the percentage of surviving of explants. Post-irradiation rooting responses of in vitro individual shoots was determined by recording days to root initiation, root number, root length $(\mathrm{cm})$ and shoot length $(\mathrm{cm})$, during and after 30 days of treatment In the case of hardened plants; plant height $(\mathrm{cm})$, number of leaves and chlorophyll content by using (Minolta chlorophyll meter SPAD-502) (Spectrum Technologies, Inc., Plainfield, IL, U.S.) were measured. The experiment was laid out in a completely randomized design (CRD) with a 5 replication. The data were analyzed by one-way analysis of variance (ANOVA) with Duncan Multiple Range Test $(p<0.05)$. The $\mathrm{LD}_{50}$ calculation using survival rates (\%) were analyzed by linear regression (Singh, 1990).

\section{Results and Discussion}

Radiosensitivity and determination of lethal dose $\left(\mathrm{LD}_{50}\right)$

In the present study, the survival rate of irradiated explants was found to decrease linearly with the increasing of the gamma doses (Fig. 2). A remarkable decrease in survival rate was observed at 40, 50, 60 and 70 Gy of gamma dosage. Meanwhile, among the treated explants maximum survival rate of $71 \%$ was recorded at $10 \mathrm{~Gy}$, followed by $69.5 \%$ at a dose of $20 \mathrm{~Gy}, 67 \%$ at $30 \mathrm{~Gy}$ and minimum of survival rate was observed following the T7 (70 Gy) treatment, where remarkably dropped from $100 \%$ to $42 \%$ at the first week of culture and $15.5 \%$ at the fourth weeks

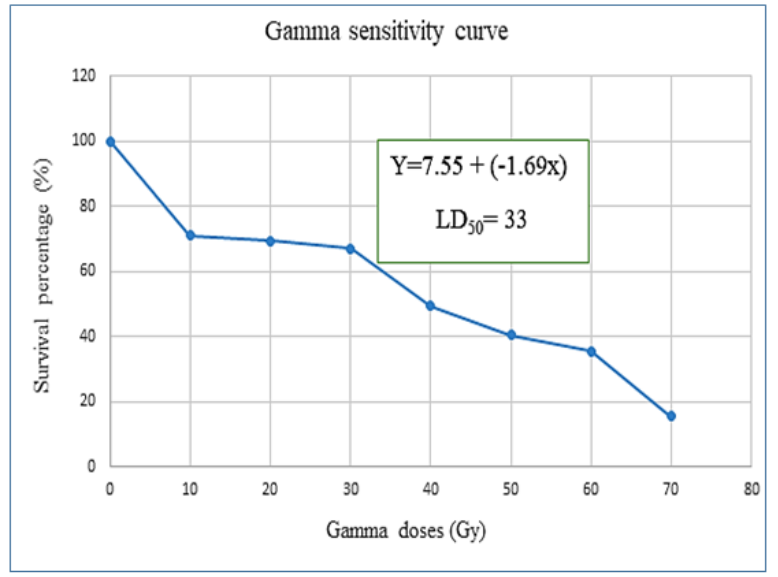

Fig. 2 Radiosensitivity test curve illustrating the effect of increasing dose of gamma rays on survival rate of individual in-vitro shoot.

of culture resulting in a total reduction of $74.5 \%$. The nonirradiated explant recorded the highest survival percentage of $100 \%$. The lethal dose $\left(\mathrm{LD}_{50}\right)$ was found to be $33 \mathrm{~Gy}$ based on the survival percentage, the estimation was carried out using linear regression analysis. Karmarkar et al. 2001 had made similar observations in cv. Basrai (AAA) which corroborate our finding.In principle, the most effective doses for mutation induction are thought to be the gamma doses lower than the $\mathrm{LD}_{50}$. As a result of these measurements, a large quantity of individual shoot was finally treated with 10, 20 and 30 Gy doses of gamma radiation and then the explants were transferred on rooting medium.

Effect of gamma irradiation on the growth of irradiated in vitro individual shoots under laboratory condition

\section{Effect on shoot elongation}

The shoot length reduced prominently with increase in gamma irradiation doses (Table 1). The shoot length was significantly lower at higher dose (30 Gy), however lower gamma doses at 10 and 20 Gy showed no significance

Table 1 Effect of gamma irradiation on the in vitro individual shoot of cultivar Tanduk after gamma irradiation

\begin{tabular}{cccccccc}
\hline \multirow{2}{*}{$\begin{array}{c}\text { Gamma } \\
\text { treatment }\end{array}$} & $\begin{array}{c}\text { Shoot } \\
\text { length }\end{array}$ & Leaf number & $\begin{array}{c}\text { Days to root } \\
\text { initiation }\end{array}$ & $\begin{array}{c}\text { Root } \\
\text { number }\end{array}$ & Root length & Plant height & $\begin{array}{c}\text { Chlorophyl } \\
1\end{array}$ (SPAD) \\
\hline T0: Control & $13.6 \pm 0.6^{\mathrm{a}}$ & $7.01 \pm 0.5^{\mathrm{a}}$ & $7.2 \pm 0.3^{\mathrm{a}}$ & $20.02 \pm 1.4^{\mathrm{a}}$ & $15.1 \pm 0.5^{\mathrm{a}}$ & $27.8 \pm 1.7^{\mathrm{a}}$ & $44.2 \pm 2.1^{\mathrm{b}}$ \\
T1: $10 \mathrm{~Gy}$ & $12.7 \pm 0.1^{\mathrm{ab}}$ & $7.02 \pm 0.3^{\mathrm{a}}$ & $11.1 \pm 1.1^{\mathrm{b}}$ & $18.3 \pm 1.3^{\mathrm{a}}$ & $13.2 \pm 0.3^{\mathrm{b}}$ & $25.5 \pm 0.5^{\mathrm{a}}$ & $49.8 \pm 3.2^{\mathrm{a}}$ \\
T2: 20 Gy & $11.6 \pm 0.2^{\mathrm{bc}}$ & $5.00 \pm 0.6^{\mathrm{ab}}$ & $12.5 \pm 1.2^{\mathrm{b}}$ & $12.1 \pm 1.3^{\mathrm{b}}$ & $12.5 \pm 0.2^{\mathrm{b}}$ & $24.4 \pm 0.3^{\mathrm{a}}$ & $42.4 \pm 3.2^{\mathrm{bc}}$ \\
T3: 30 Gy & $10.4 \pm 0.2^{\mathrm{c}}$ & $4.99 \pm 0.4^{\mathrm{c}}$ & $12.3 \pm 2.5^{\mathrm{b}}$ & $8.2 \pm 0.40^{\mathrm{c}}$ & $10.1 \pm 0.4^{\mathrm{c}}$ & $21.2 \pm 0.4^{\mathrm{b}}$ & $39.6 \pm 3.0^{\mathrm{c}}$ \\
\hline
\end{tabular}

Means sharing the same letters within a column are not significantly different from each other at $P<0.05$ after testing Duncan test. 


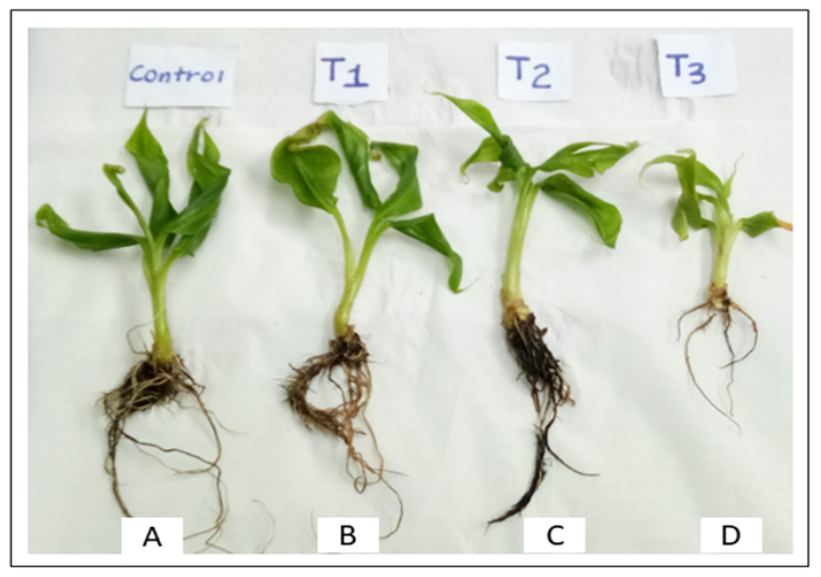

Fig. 3 Irradiated and rooted in vitro individual shoot explants 30 days after irradiation (A): Control, (B): $10 \mathrm{~Gy},(\mathrm{C}): 20 \mathrm{~Gy}$ and (D): 30 Gy

difference over the control. The highest shoot length (13.6 $\mathrm{cm})$ was observed at control treatment, followed by $10 \mathrm{~Gy}$ $(12.7 \mathrm{~cm}), 20 \mathrm{~Gy}(11.6 \mathrm{~cm})$, and the shortest shoot length $(10.4 \mathrm{~cm}$ ) was observed at $30 \mathrm{~Gy}$ (Fig. 3). As reported by Majeed et al. (2009) and Khalil et al. (1986), reduction of a shoot and root growth at higher doses of gamma rays is due to reduced mitotic activity in meristematic tissues and reduced moisture contents of explants. In agreement with the present investigations, Al-Salhi et al. (2004) observed that decrease in shoot length is in proportion with increasing gamma dose in corn Nahrung. Similar conclusion by Wi et al. (2007) stated that the reason could be due to disruption of hormonal balance and enzymatic activities. A similar results have been reported by several researchers (Datta and Banerjee 1995; Fereol, 1996) on the inhibitory effects of high doses of gamma irradiation on shoot growth, reported that the inhibition might be due to turbulences in physio-biochemical processes related to the action of gibberellic acid, which typically stimulates cell division and cell elongation and higher dose kills meristematic cells, or damage cells producing fewer progeny cells and causing inability of irradiated tissues cells to absorb available nutrient, which leads to reduced growth.

\section{Effects on rooting}

Significant difference was observed in rooting of explants subjected to the higher dose of $\gamma$ (30 Gy) (Table 1). It was observed that increase in gamma irradiation dose resulted inhibition of root growth. Non-treated explants had the best rooting ability with the maximum number of root per explant (20) within a short period of time (6 d), with the highest length of a root $(15.1 \mathrm{~cm})$. The longer period in

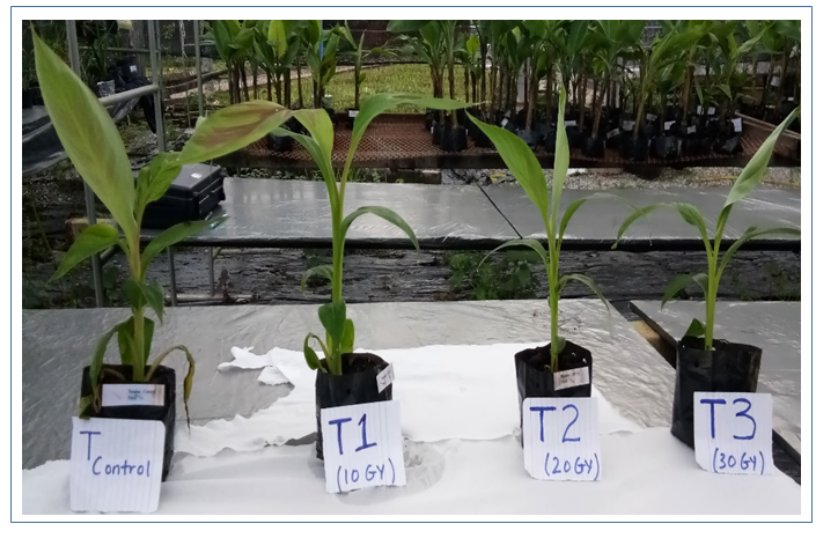

Fig. 4 Acclimatizaion of irradiated plantlets

rooting (12 d) and lowest number of root per explant (8) with shortest root length $(10.1 \mathrm{~cm})$ were recorded at $30 \mathrm{~Gy}$ treatment. Generally, the non-treated explants exhibited better rooting performance in all root growth parameter. This could be due to perturbations of hormones balance inside the explant and the activity of hormone synthesized and transported from tip to the site of action or exogenous supply of auxin used for rooting. The inhibition of rooting at higher gamma doses have been reported by several researchers (Karmarkar et al. 2001, Wi et al. 2007 and Kiong et al. 2008) who described that rise of radiation dose increases plants sensitivity to gamma rays effect and reduces the amount of endogenous growth regulators, particularly the auxin and cytokines. This would resulted breakdown, or lack of synthesis and or disruption of hormonal balance and enzymatic activities. In contrast, Muthusamy and Jayabalan, (2014) reported that the days to shoot and root initiation was faster when the explants exposed to gamma radiation at a lower dose in cotton seed.

Growth assessment of irradiated in vitro individual plantlets in the nursery condition

\section{Effect on leaf formation and plant height}

From the data obtained the leaf formation of irradiated plantlets with $10 \mathrm{~Gy}$ and 20 Gy was not significantly different over the control but treated explants with $30 \mathrm{~Gy}$ showed significant difference with that of control. The maximum number of leaves (7) was recorded at control plants. The lowest leaf number (5) was observed at $30 \mathrm{~Gy}$ compared with all treatments. Leaves number decreased in proportion with increasing gamma dose. All explants exposed to gamma dose showed a reducing trend in leaves 
number and found to be inhibitory. From the data obtained, gamma radiation had no significant impact on leaf number in all treated explant rather it showed reduction trend in leaf number as the gamma dose increases. In contradiction with earlier findings, Yadav, (2016) had observed highly significant impact on leaf number in $\mathrm{Cv}$. decurrens in a lower dose of gamma. However, our experiments are consistent with recent studies by Jala, (2011), who reported that higher concentration of gamma rays decreased the number of leaves in Torenia fourmieri plant. The data collected on plant height showed significance differences in plant height of banana seedlings subjected to higher $\gamma$ dose (20 and 30 Gy). The average seedling height declined significantly from the control to the highest dose of $\gamma$. The tallest seedling observed was $27.8 \pm 1.7 \mathrm{~cm}$ in control, followed by $25.5 \pm 0.5$ in $10 \mathrm{~Gy}, 25.4 \pm 0.3$ in $20 \mathrm{~Gy}$ and $21.2 \pm 0.4$. Furthermore, Suprasanna et al. (2009) identify morphological variation resulted from mutagenic treatment in banana plant by some agronomic characters such as plant height and leaf shape and they observed dwarf banana plants derived from in vitro mutagenesis.

\section{Effects on chlorophyll content}

The effect of gamma irradiation on chlorophyll content showed 10 Gy showed significant diffence over the control treatment (Table 1). The highest chlorophyll content (49.8) was recorded at 10 Gy treated plantlets, followed by 44.6, 42.4 and 39.6 in treatment $20 \mathrm{~Gy}, 30 \mathrm{~Gy}$, and control respectively. Our experiments are consistent with recent studies by Sakr et al. (2013) stated that exposure of Dracaena surculosa plant to 10 Gy of gamma radiation gave the highest content of chlorophylls. In another study by Atak et al. (2007) reported that an increase in chlorophyll was observed in Paulownia tomentosa plants that were exposed to $20 \mathrm{~Gy}$ gamma irradiation , about $20.6 \%$ of chlorophyll content increased. Similarly, in our investigation, the chlorophyll contents of irradiated plantlets of were displayed a gradual increment at a low dose of gamma rays. The reason as reported by Ferreira-Castro et al. (2007) indicated that the chlorophyll level increases when the explants exposed to low levels of radiation as a result of an activated enzyme system. This would have enhanced photosynthetic rate and therefore gave larger yield in the field.

\section{Conclusion}

In conclusion, the result from the current experiment indicated that $\gamma$ treatments induced morphological and physiological variations on banana cultivar Pisang Tanduk. Lower dose of $\gamma$ irradiation induced positive impact on the growth of in vitro plantlets during the multiplication phase and rooting stage, whereas higher $v$ irradiation had caused a negative impact on the growth, in terms of higher mortality rate and reduction in growth.

Therefore, we suggested that $\gamma$ radiation can be usefully employed in banana for induction of desirable mutations and further, work on field performance of mutants, in terms of early flowering, yield quantity, quality and other agronomical traits need to be looking next.

\section{Acknowledgement}

The author would like to acknowledge Islamic Development Bank Group (IDBG) for generous funding of this research.

\section{References}

Al-Salhi M, Ghannam MM, Al-Ayed MS, El-Kameesy SU, Roshdy S (2004) Effect of gamma irradiation on the biophysical and morphological properties of corn Nahrung. Molec Nutri and Food Res. 48:95-98

Ashraf M, Cheema AA, Rashid M, Qamar Z (2004) Effect of gamma rays on $\mathrm{Ml}$ generation in basmati rice. Pak $\mathrm{J}$ Bot. 35:791-796

Atak C, Celik O, Olgun A, Alikamanoğlu S, Rzakoulieva A (2007) Effect of magnetic field on peroxidase activities of soybean tissue culture. Biotechnol Equip. 21:166-171

Banerjee A, Suprasanna P, Variyar PS, Sharma A (2015) Gamma irradiation inhibits wound induced browning in shredded cabbage. Food Chemi. 173:38-44

Datta SK, Banerji BK (1995). Improvement of garden chrysanthemum through induced mutation. Flora and Fauna. 1:1-4

Féréol L, Louis S, Luce A (1996) Effects of gamma radiation on in vitro plantlets of Alpinia purpurata. J Horti Sci. 71:243-247

Ferreira-Castro F, Aquino S, Greiner R, Ribeiro D, Reis T, Correa B (2007) Effects of gamma radiation on maize samples contaminated with Fusarium verticillioides. Appl Radiat Isot. 65:927-933

Fu HW, Li YF, Shu QY (2008) A revisit of mutation induction by gamma rays in rice (Oryza sativa L.): implications of microsatellite markers for quality control. Molec Bred. 22: 281-288

Jain SM, Suprasanna P (2011) Induced mutations for enhancing nutrition and food production. Gene Conserve. 40:201-215

Jala A (2011) Morphological change due to effects of acute gamma ray on wishbone flower (Torenia fourmieri) in vitro. Inter Transac J Enginee Manage App Sci Tech. 2:375-384 
Javed MA, Chai M, Othman R (2004) Study of resistance of Musa acuminata to Fusarium oxysporum using RAPD markers. Biologia Plantarum. 48:93-99

Karmarkar VM, Kulkarni VM, Suprasanna P, Bapat VA, Rao PS (2001) Radio-sensitivity of in vivo and in vitro cultures of banana cv. Basrai (AAA). Fruits. 56:67-74

Kharkwal M.C, Shu QY (2009) The role of induced mutations in world food security. In: Induced plant mutations in the genomics era, (pp. 33-38). Food Agri Organi, UN Rome

Kiong AA, Ling Pick, Grace Lai SH, Harun AR (2008) Physiological responses of Orthosiphon stamineus plantlets to gamma irradiation. Am-Eurasian J Sustain Agric. 2:135-149

Kovacs E, Keresztes A (2002) Effect of gamma and UV-B/C radiation on plant cells. Micron. 33:199-210

Kumar N (2016) Problems and prospects of banana breeding in India. J Horti Sci. 1:77-94

Majeed A, Muhammad Z, Ahmad H, Khan AUR (2009) Gamma Irradiation Effects on Some Growth Parameters of Lepidium Sativum L. American-Eurasian J Sustai Agri. 3:424-427

Mbaye G, Soumboundou M, Diouf LAD, Ndong B, Djiboune AR, Sy PM, Diarra M (2017) Evaluation of the Effects of Irradiation of Peanut Grain by a Gamma-Ray Beam on Culture. Ope J Biophy. 7:94

Murashige T, Skoog F (1962) A revised medium for rapid growth and bio assays with tobacco tissue cultures. Physiologia plantarum. 15:473-497

Muthusamy A, Jayabalan N (2014) Radiation and chemical mutagen induced somaclonal variations through in vitro organogenesis of cotton Gossypium hirsutum L. Intern J radiation bio. 90:1229-1239

Roux NS, Toloza A, Dolezel J, Panis B (2004) Usefulness of embryogenic cell suspension cultures for the induction and selection of mutants in Musa spp. In: Banana improvement: cellular, molecular biology and induced mutations, (pp. 33-43). Sci publisher Inc USA

Sakr SS, El-Khateeb MA, Taha HS, Esmail SA (2013) Effect of gamma irradiation on in vitro growth, chemical composition and anatomical structure of Dracaena surculosa L. J Appl Sci Res. 9:3795-3801

Singh HP (1990) Country paper report on banana and plantain-India. Banana and Plantain R and D in Asia and the Pacific INIBAP. 161-185

Suprasanna P, Sidha M, Bapat, VA (2009) Integrated approaches of mutagenesis and in vitro selection for crop improvement. In: Plant Tissue Culture and Molecular Markers: Their Roles in Improving Crop Productivity, (pp. 73-91). Int. Pub. Hous, India

Wi SG, Chung BY, Kim JS (2007) Effects of gamma irradiation on morphological changes and biological responses in plants. Micron. 38:553-564

Yadav V (2016) Effect of gamma radiation on various growth parameters and biomass of Canscora decurrens Dalz. Interna J Herbal Medic. 4:109-115

Yamaguchi H, Nagatomi S, Morishita T, Degi K, Tanaka A, Shikazono N, Hase Y (2003) Mutation induced with ion beam irradiation in rose. In: Nuclear Instruments and Methods in Physics Research Section B: Beam Interactions with Materials and Atoms. 206:561-564 